\title{
Correction to: Recommended Best Practices for Lyophilization Validation-2021 Part I: Process Design and Modeling
}

\author{
Feroz Jameel $^{1} \cdot$ Alina Alexeenko $^{2} \cdot$ Akhilesh Bhambhani $^{9} \cdot$ Gregory Sacha $^{4} \cdot$ Tong Zhu $^{1} \cdot$ Serguei Tchessalov $^{5}$. \\ Lokesh Kumar $^{6} \cdot$ Puneet Sharma $^{6} \cdot$ Ehab Moussa $^{1} \cdot$ Lavanya Iyer $^{7} \cdot$ Rui Fang $^{3} \cdot$ Jayasree Srinivasan $^{4}$. \\ Ted Tharp ${ }^{1} \cdot$ Joseph Azzarella $^{8} \cdot$ Petr Kazarin $^{2,10} \cdot$ Mehfouz Jalal $^{2}$
}

Published online 18 October 2021

Correction to: AAPS PharmSciTech volume 22, Article number: 221 (2021) https://doi.org/10.1208/s12249-021-02086-8

In this article the affiliation details for Rui Fang were incorrectly given as 'Merck, West Point, PA USA' but should have been 'Merck, Kenilworth, NJ, USA'. In addition, during the production process, the typesetter inadvertently omitted the graphical abstract.

The original article has been corrected

Publisher's note Springer Nature remains neutral with regard to jurisdictional claims in published maps and institutional affiliations.

The original article can be found online at https://doi.org/10. 1208/s12249-021-02086-8.

\footnotetext{
${ }^{1}$ Abbvie, North Chicago, IL, USA

${ }^{2}$ Birck Nanotechnology Center, Purdue University, 1205 W State St, West Lafayette, IN 47907, USA

${ }^{3}$ Merck, Kenilworth, NJ, USA

${ }^{4}$ Baxter Healthcare, Bloomington, IN, USA

${ }^{5}$ Pfizer, Andover, MA, USA

${ }^{6}$ Genentech, South San Francisco, CA, USA

${ }^{7}$ BMS, New Brunswick, NJ, USA

${ }^{8}$ Fresenius Kabi, Buffalo, NY, USA

${ }^{9}$ Ultragenyx pharmaceutical Inc, Brisbane, CA, USA

${ }^{10}$ To whom correspondence should be addressed. (e-mail: pkazarin@ purdue.edu
} 